\title{
Editorial
}

\section{Impact of Multi-Drug Sequential Therapy on Survival in Patients with Unresectable Hepatocellular Carcinoma}

\author{
Masatoshi Kudo \\ Department of Gastroenterology and Hepatology, Kindai University Faculty of Medicine, Osaka, Japan
}

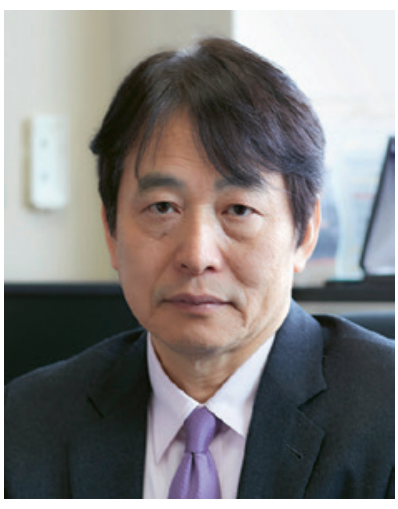

Prof. M. Kudo

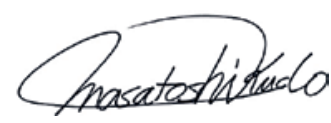

Editor Liver Cancer

\section{Keywords}

Molecular targeted therapy - Sorafenib · Regorafenib . Lenvatinib - Sequential therapy

Sorafenib was approved in Europe and the United States in 2007 [1, 2] and in Japan in 2009. Since its approval, molecular targeted therapy has extended survival in patients with unresectable hepatocellular carcinoma (HCC). This editorial describes how the use of sorafenib as monotherapy or as sequential therapy with other targeted agents $[3,4]$ led to improved survival in patients with HCC.

karger@karger.com www.karger.com/lic

Karger ${ }^{\prime \prime} \div$

GOPEN ACCESS
(C) 2021 The Author(s)

Published by S. Karger AG, Basel

This is an Open Access article licensed under the Creative Commons Attribution-NonCommercial-4.0 International License (CC BY-NC) (http://www.karger.com/Services/OpenAccessLicense), applicable to the online version of the article only. Usage and distribution for commercial purposes requires written permission.

\section{Outcomes of Sorafenib Treatment between 2007 and 2017: Survival before and after the Introduction of Sorafenib in Japan}

In the 2019 International Liver Congress by the European Association for the Study of the Liver, Sensui et al. [5] reported that the introduction of sorafenib increased the survival rate of patients with advanced HCC. Specifically, the median overall survival (OS) of patients with advanced HCC was 9.1 months before the introduction of sorafenib (pre-sorafenib period: 2003-2008), and it did not change significantly in the period immediately following the introduction of sorafenib (period I: 20092012) at 8.9 months; however, survival improved significantly to 14.3 months in the subsequent 4 years (period II: 2013-2017) (Table 1) [5]. The best explanation for this trend is that adverse events were not managed effectively immediately after the introduction of sorafenib, resulting in a shorter treatment period that decreased its effectiveness. Treatment duration was significantly shorter $(2.5$ months) in period I (2009-2012) than in period II (4.4 months) (2013-2017). This suggests that the management of adverse events to sorafenib improved with increased clinical experience, leading to a longer treatment duration that contributed to longer survival in advanced HCC. The increase in the median duration of sorafenib therapy and survival was more substantial between 2013

Masatoshi Kudo

Department of Gastroenterology

Kindai University Faculty of Medicine

377-2, Ohno-Higashi, Osaka-Sayama, Osaka 589-8511 (Japan)

m-kudo@med.kindai.ac.jp 
Table 1. OS and DC in patients who received systemic therapy according to treatment period

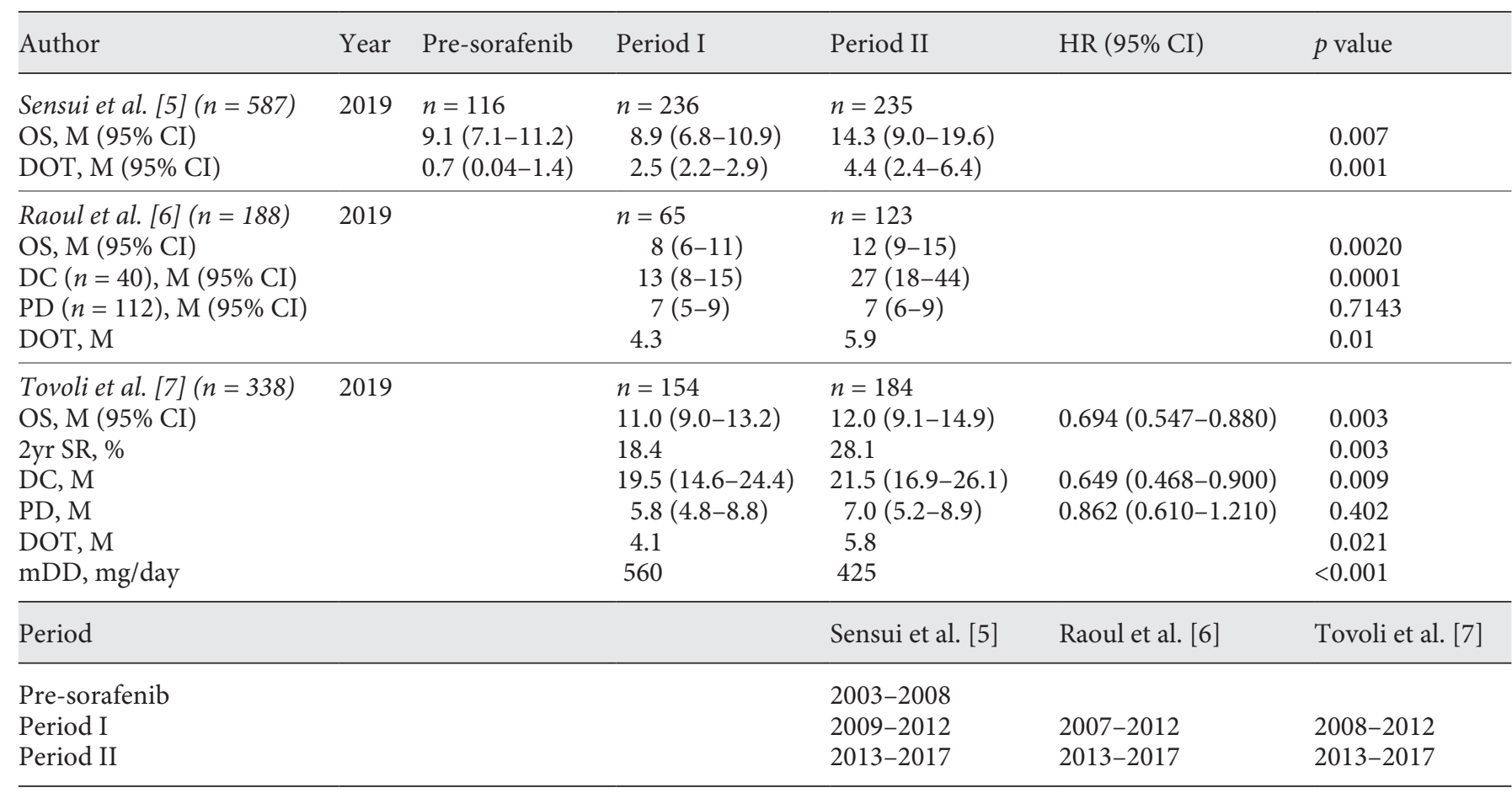

OS, overall survival; DC, disease control; HR, hazard ratio; CI, confidence interval; PD, progressive disease; DOT, duration of treatment; $\mathrm{mDD}$, median daily dose; $2 \mathrm{yr} \mathrm{SR}, 2$-year survival rate.

and 2017, when strategies for managing adverse events were being established, than in the period before and after the introduction of tyrosine kinase inhibitor therapy.

\section{Treatment Outcomes for Sorafenib in 2007-2017: Studies from outside Japan}

Raoul et al. [6] reported the median OS results for period I (2007-2012) and period II (2013-2017). These authors found that median OS was 8 months for period I and 12 months for period II, demonstrating a clear improvement in survival (Table 1).

The median OS of patients who achieved disease control was also markedly better from 2013 to 2017 than from 2007 to 2012 (27 vs. 13 months; Table 1), and the median OS of patients with progressive disease was a short 7 months for both periods (Table 1). Raoul et al. [6] identified factors that contribute significantly to survival in a multivariate analysis, including 188 patients with advanced HCC treated with sorafenib between 2007 and 2017. These factors are Child-Pugh grade A, alpha-fetoprotein (AFP) $\leq 200 \mathrm{ng} / \mathrm{mL}$, absence of vascular invasion, and treatment between 2013 and 2017 (hazard ratio [HR], 0.66 ; $95 \%$ confidence interval $[\mathrm{CI}], 0.44-1.00 ; p=0.05$ ) (Table 2).

Tovoli et al. [7] reported similar results in a study that compared outcomes between 2008 and 2012 (period I) and 2013 and 2017 (period II). There were no significant imbalances in patient characteristics. The median OS of patients with advanced HCC treated with sorafenib was significantly better in period II than in period I (12.0 vs. 11.0 months; HR, 0.694; 95\% CI, 0.547-0.88; $p=0.003$ ) (Table 1). Similar to Raoul et al. [6], Tovoli et al. [7] performed subgroup analyses in patients who achieved disease control and patients with progressive disease. The median OS improved between periods I and II in patients who achieved disease control (19.5 vs. 21.5 months; HR, 0.649 ; 95\% CI, $0.468-0.900 ; p=0.010$ ), whereas it did not differ significantly between periods I and II in patients with progressive disease (5.8 vs. 7.0 months; $\mathrm{HR}, 0.862$; 95\% CI, 0.610-1.219; $p=0.402$ ) (Table 1).

These 2 studies showed exactly the same results. First, survival clearly improved after 2013, when effective management of adverse reactions to sorafenib was achieved through the development of appropriate treatment strat- 
Table 2. Prognostic factors in patients who received sorafenib treatment during 2007-2017: multivariate analysis $(n=188)$

Table 3. Dose reduction status due to adverse events during sorafenib treatment by treatment period

\begin{tabular}{lcc}
\hline Parameters & OR $(95 \% \mathrm{CI})$ & $p$ value \\
\hline Child-Pugh, A versus B & $1.82[1.07-3.10]$ & $<\mathbf{0 . 0 3}$ \\
Bilirubin, $\leq 18.3$ versus $>18.3 \mu \mathrm{mol} / \mathrm{L}$ & $0.84[0.55-1.31]$ & 0.44 \\
Albumin $\leq 33$ versus $>33 \mathrm{~g} / \mathrm{L}$ & $1.02[0.65-1.59]$ & 0.95 \\
AFP, $\leq 200$ versus $>200 \mathrm{ng} / \mathrm{mL}$ & $2.03[1.34-3.07]$ & $<\mathbf{0 . 0 0 1}$ \\
PS, 0 versus 1 & $1.46[0.96-2.21]$ & 0.07 \\
Vascular invasion, yes versus no & $1.54[1.00-2.37]$ & $<\mathbf{0 . 0 5}$ \\
Metastases, no versus yes & $0.78[0.42-1.47]$ & 0.44 \\
Period of treatment, 2007-2012 versus 2013-2017 & $0.66[0.44-1.00]$ & $\mathbf{0 . 0 5}$ \\
\hline
\end{tabular}

Bold type denotes statistical significance. AFP, alpha-fetoprotein; PS, performance status. Modified from Ref. [6].

\begin{tabular}{lllr}
\hline & $\begin{array}{l}\text { 2008-2012 } \\
\text { period }(n=154)\end{array}$ & $\begin{array}{l}\text { 2013-2017 } \\
\text { period }(n=184)\end{array}$ & $p$ value \\
\hline Dose reduction to $400 \mathrm{mg} /$ day & $113(75.3)$ & $157(86.4)$ & 0.009 \\
Re-escalation to $800 \mathrm{mg} /$ day & $34 / 113(30.2)$ & $35 / 157(22.0)$ & 0.341 \\
Dose reduction to $200 \mathrm{mg} /$ day & $21(18.2)$ & $56(35.2)$ & $<0.001$ \\
Re-escalation to $400 \mathrm{mg}$ /day & $15 / 21(71.4)$ & $34 / 56(60.7)$ & 0.691 \\
\hline
\end{tabular}

Data are expressed as frequencies (percentage). Modified from Ref. [7]. egies. Second, even survival in patients who achieved disease control improved from period I to period II. Tovoli et al. [7] performed a landmark analysis comparing 12 and 24 month survival curves between periods I and II. The HR for OS was consistent between the 12 month (HR, 0.529; 95\% CI, 0.330-0.770; $p=0.001$ ) and 24 month (HR, $0.488 ; 95 \%$ CI, $0.271-0.882 ; p=0.017$ ) curves, thus demonstrating the robustness of the data.

Tovoli et al. [7] explain that one reason for the improved median OS in period II compared with period I was the significantly higher rate of dose reduction in period II ( 86.4 vs. $75.3 \%)$, as well as the significantly higher rate of dose reduction to $400 \mathrm{mg}$ ( $86.4 \mathrm{vs}$. $75.3 \%$ ) or to 200 mg (35.2 vs. $18.2 \%$ ) (Table 3) [7].

Other major reasons for the improved OS were that progressive disease and hepatic failure were consistent factors leading to discontinuation of sorafenib in both 2 periods, but the rate of intolerance to sorafenib decreased significantly from 20.8 to $9.4 \%$ (Table 4 ). In other words, improving the management of sorafenib-related adverse events decreased the number of patients who discontinued treatment due to adverse events. Factors identified as poor prognostic factors in the multivariate analysis were (1) Child-Pugh grade B, (2) poor performance status, (3) presence of macrovascular invasion, (4) AFP $\geq 400 \mathrm{ng} /$
Table 4. Reasons for sorafenib discontinuation according to treatment period

\begin{tabular}{lllr}
\hline $\begin{array}{l}\text { Reason for } \\
\text { discontinuation }\end{array}$ & $\begin{array}{l}\text { 2008-2012 } \\
\text { period }(n=154)\end{array}$ & $\begin{array}{l}\text { 2013-2017 } \\
\text { period }(n=180)\end{array}$ & $p$ value \\
\hline Progression & $98(63.6)$ & $129(71.7)$ & 0.127 \\
Intolerance & $32(20.8)$ & $17(9.4)$ & $<0.001$ \\
Liver failure & $20(13.0)$ & $26(14.4)$ & 0.752 \\
Other & $4(2.6)$ & $8(4.4)$ & 0.557 \\
\hline
\end{tabular}

Four patients are still receiving sorafenib in this group. Cited from Ref. [7].

$\mathrm{mL},(5)$ absence of hand-foot-skin reaction, and (6) undergoing sorafenib treatment during period I (HR, 0.728; 95\% CI, 0.581-0.937; $p=0.013$ ) (Table 5).

\section{Multi-Drug Sequential Therapy}

Sequential therapy with 2 or more drugs was shown to improve survival in several studies. In the RESORCE trial, survival after sequential therapy with sorafenib and regorafenib was 26 months [8]. Real-world clinical data 
Table 5. Prognostic factors in patients with HCC who received sorafenib treatment: uni- and multivariate analyses

\begin{tabular}{|c|c|c|c|c|c|c|}
\hline Variable & HR & $95 \% \mathrm{CI}$ & $p$ value & HR & $95 \% \mathrm{CI}$ & $p$ value \\
\hline Male gender & 1.034 & $0.815-1.311$ & 0.784 & & & \\
\hline Viral etiology & 1.011 & $0.722-1.300$ & 0.733 & & & \\
\hline Time since first HCC diagnosis $>12$ months & 0.888 & $0.789-1.000$ & 0.049 & & & 0.723 \\
\hline Macrovascular invasion & 1.770 & $1.373-2.282$ & $<0.001$ & 1.722 & $1.331-2.622$ & $<0.001$ \\
\hline Extrahepatic spread & 1.250 & $0.989-1.584$ & 0.095 & & & 0.111 \\
\hline $\mathrm{AFP} \geq 400 \mathrm{ng} / \mathrm{mL}$ & 1.486 & $1.147-1.924$ & 0.003 & 1.328 & $1.024-1.724$ & 0.033 \\
\hline Dermatological adverse events & 0.562 & $0.436-0.725$ & $<0.001$ & 0.624 & $0.482-0.808$ & $<0.001$ \\
\hline Period of treatment (2013-2017 vs. $2008-2012)$ & 0.694 & $0.547-0.880$ & 0.003 & 0.728 & $0.581-0.937$ & 0.013 \\
\hline
\end{tabular}

AFP, alpha-fetoprotein; HCC, hepatocellular carcinoma; HR, hazard ratio; CI, confidence interval. Modified from Ref. [7].

Table 6. Profiles of patients eligible for sequential therapy after sorafenib

\begin{tabular}{|c|c|c|c|c|}
\hline Author; journal & Patients & $\begin{array}{l}\text { Percent of } \\
\text { candidates for } \\
\text { second-line } \\
\text { therapy* }\end{array}$ & $\begin{array}{l}\text { Percent of } \\
\text { regorafenib } \\
\text { candidate }^{* *}\end{array}$ & $\begin{array}{l}\text { Contributing factor to second- } \\
\text { line therapy }\end{array}$ \\
\hline $\begin{array}{l}\text { Ogasawara et al. [13]; Invest New } \\
\text { Drugs. 2018; 36(2):332-9 }\end{array}$ & $\begin{array}{l}185 \text { cases } \\
\text { CP-A, PS } 0-1 \\
\text { Sorafenib } 800 \mathrm{mg}\end{array}$ & $70 \%$ & $45.7 \%$ & $\begin{array}{l}\text { CP score } 5 \\
\text { PS } 0\end{array}$ \\
\hline $\begin{array}{l}\text { Uchikawa et al. [15]; Hepatol Res. } \\
\text { 2018; 48(10):814-20 }\end{array}$ & $\begin{array}{l}147 \text { cases (excluding } \\
\text { discontinuation due to AE) } \\
\text { CP-A, PS } 0-1 \\
\text { Sorafenib } 800 \mathrm{mg}\end{array}$ & $50.3 \%$ & $30.6 \%$ & $\begin{array}{l}\text { Alb }>3.5 \mathrm{~g} / \mathrm{dL} \\
\text { MVI }(-)\end{array}$ \\
\hline $\begin{array}{l}\text { Yukimoto et al. [17]; JJCO. 2019; } \\
49(1): 42-47\end{array}$ & $\begin{array}{l}138 \text { cases (excluding } \\
\text { discontinuation due to AE) } \\
\text { CP-A } 85.5 \% \\
\text { Sorafenib starting dose N/A }\end{array}$ & na & $44.2 \%$ & ALBI score $<-2.53$ \\
\hline $\begin{array}{l}\text { Takeda et al. [18]; Cancers. 2019; } \\
\text { 11(9):1256 }\end{array}$ & $\begin{array}{l}190 \text { cases } \\
\text { CP-A, PS 0-1 } \\
\text { Sorafenib starting dose N/A }\end{array}$ & na & $29 \%$ & $\begin{array}{l}\mathrm{Alb}>3.7 \mathrm{~g} / \mathrm{dL} \\
\text { ALBI score }<-2.33 \\
\Delta \mathrm{Alb}<-0.2 \mathrm{~g} / \mathrm{dL} \text { at } 4 \text { week } \\
\triangle \mathrm{ALBI} \text { score }<0.255 \text { at } 4 \text { week }\end{array}$ \\
\hline
\end{tabular}


Table 7. Conditions for high second-line treatment rate at the time of sorafenib initiation

\begin{tabular}{llll}
\hline Author & $\begin{array}{l}\text { Condition for } \\
\text { sorafenib } \\
\text { introduction }\end{array}$ & $\begin{array}{l}\text { Percent of } \\
\text { candidates for } \\
\text { second-line } \\
\text { treatment, } \%\end{array}$ & $\begin{array}{l}\text { Percent of } \\
\text { regorafenib } \\
\text { candidate, }\end{array}$ \\
\hline Ogas \% \\
\hline Kuzuya et al. [14] & CP score 5 & 78.4 & 45.7 \\
\hline Uchikawa et al. [15] & CP score 5 & 72.4 & 46.6 \\
\hline
\end{tabular}

* Patients who fulfilled Child-Pugh A and PS $\leq 1$ at the PD on sorafenib. ** Patients who fulfilled Child-Pugh A liver function, PS $\leq 1$, and tolerable to sorafenib at the PD on sorafenib. CP score, Child-Pugh score; MVI, Macrovascular invasion; PS, performance status; PD, progressive disease. from many studies were recently published. Ogasawara et al. [9] found that the median OS was not reached from the start of sorafenib treatment and was a long 17.3 months from the start of regorafenib treatment. One factor that explains this finding is that patients who received sorafenib and regorafenib were later treated with lenvatinib. The median OS was not reached from the start of regorafenib treatment in 17 patients who later received lenvatinib, whereas it was 8.7 months from the start of regorafenib treatment in 20 patients who were not treated with lenvatinib. In addition, from the start of sorafenib treatment, median OS was not reached in the 17 patients who later received lenvatinib and was 17.3 months in the 20 patients who did not $(p<0.001)$. These findings demonstrate that molecular targeted therapy with sorafenib, regorafenib, and lenvatinib is highly effective and extends survival. Hiraoka et al. [10] from the Real-life Practice Experts for HCC (RELPEC) Study Group reported similar results in 84 patients: the median OS was a long 46.4 months from the start of firstline therapy. That study investigated the efficacy of 2 -drug sequential therapy with sorafenib followed by lenvatinib $(n=48)$ as well as 3-drug sequential therapy with sorafenib followed by regorafenib and then lenvatinib $(n=31)$, providing further evidence that lenvatinib markedly extends survival when used in second- and third-line therapy.

Hiraoka et al. $[10,11]$ also showed that OS from the start of treatment is strongly correlated with the total duration of treatment with multiple agents. The total duration of treatment with tyrosine kinase inhibitors in sequential therapy is significantly correlated with OS when lenvatinib is the last-line therapy.

Impact of Multi-Drug Sequential Therapy in HCC
Wang et al. [12] also reported a long median OS from the start of regorafenib treatment, which was 12.4 months in 38 patients, and the percentage of patients who received post-regorafenib therapies after stopping regorafenib due to disease progression was high at $86.4 \%(n=$ $22)$. Among 14 patients who received lenvatinib as thirdline $(n=10)$ or fourth-line $(n=4)$ therapy, the response rate to lenvatinib was $42.9 \%$ and the disease control rate was $85.7 \%$, demonstrating that lenvatinib is effective as third- and fourth-line therapy as well. These findings indicate that multi-drug sequential therapy with last-line lenvatinib has a marked impact on survival.

Several studies have investigated the patient groups that would benefit the most from multi-drug sequential therapy after sorafenib. Favorable indicators identified include a good Child-Pugh score (5 points), high albumin level ( $\geq 3.5 \mathrm{~g} / \mathrm{dL})$, and a good albumin-bilirubin (ALBI) score (either $\leq-2.53$ or $\leq-2.33$ ), indicating that good liver function is the most important key factor. Absence of vascular invasion is another good prognostic factor that has been identified in clinical practice in Japan (Table 6) [13-18]. Data from a 3-center study show that 65.8$78.4 \%$ of patients would be good candidates for secondline therapy after sorafenib if the conditions for sorafenib introduction were more strict, and a particularly high $40.5-45.7 \%$ of these patients would be candidates for regorafenib (Table 7) [13-15].

Studies from outside Japan show similar results. A study of patients who underwent multi-drug sequential therapy between 2014 and 2019 reported a median OS of 35 months, and patients received up to 5 lines of therapy [19]. In this study, lenvatinib was also frequently used as second-line (12.9\%) and third-line (10.5\%) therapy. These results further demonstrate the importance of 
Table 8. Characteristics of patients who received sequential therapy

\begin{tabular}{|c|c|c|c|c|c|}
\hline \multirow[t]{2}{*}{ Characteristics } & \multicolumn{2}{|c|}{1 line } & \multicolumn{2}{|c|}{$\geq 2$ lines } & \multirow[t]{2}{*}{$p$ value } \\
\hline & $n$ & $\%$ & $n$ & $\%$ & \\
\hline \multicolumn{6}{|l|}{ CPS } \\
\hline $\mathrm{A}$ & 20 & 42.6 & 43 & 75.4 & \multirow{3}{*}{0.003} \\
\hline B & 25 & 53.2 & 13 & 22.8 & \\
\hline $\mathrm{C}$ & 2 & 4.3 & 1 & 1.8 & \\
\hline \multicolumn{6}{|l|}{ ALBI } \\
\hline A & 10 & 15.6 & 26 & 40.6 & \multirow{3}{*}{0.001} \\
\hline B & 44 & 68.8 & 37 & 57.8 & \\
\hline $\mathrm{C}$ & 10 & 15.6 & 1 & 1.6 & \\
\hline \multicolumn{6}{|l|}{ Lesions, $n$} \\
\hline 1 & 15 & 19.7 & 10 & 15.4 & \multirow{4}{*}{$<0.001$} \\
\hline 2 & 9 & 11.8 & 10 & 15.4 & \\
\hline 3 & 9 & 11.8 & 31 & 47.7 & \\
\hline$>3$ & 43 & 56.6 & 14 & 21.5 & \\
\hline \multicolumn{6}{|l|}{ AFP } \\
\hline$\geq 200 \mu \mathrm{g} / \mathrm{L}$ & 34 & 45.9 & 15 & 24.2 & \multirow{2}{*}{0.008} \\
\hline$\leq 200 \mu \mathrm{g} / \mathrm{L}$ & 40 & 54.1 & 47 & 75.8 & \\
\hline \multicolumn{6}{|c|}{ Vascular invasion } \\
\hline Yes & 53 & 63.1 & 24 & 35.3 & \multirow{2}{*}{0.001} \\
\hline No & 31 & 36.9 & 44 & 64.7 & \\
\hline \multicolumn{6}{|l|}{ BCLC } \\
\hline 0 & 0 & 0 & 0 & 0.0 & \multirow{5}{*}{$<0.001$} \\
\hline A & 0 & 0 & 0 & 0.0 & \\
\hline B & 0 & 0 & 16 & 25.0 & \\
\hline C & 66 & 97.1 & 47 & 73.4 & \\
\hline $\mathrm{D}$ & 2 & 2.9 & 1 & 1.6 & \\
\hline
\end{tabular}

CPS, Child-Pugh score; ALBI, albumin-bilirubin; AFP, alphafetoprotein; BCLC, Barcelona Clinic Liver Cancer. Pearson's $\chi^{2}$ test for categorical variables. Wilcoxon test for continuous data. Modified from Ref. [19].

multi-drug sequential therapy with lenvatinib as secondand third-line treatment for extending survival in advanced HCC. In that study, important patient factors leading to successful sequential therapy were good liver function, $\leq 3$ tumors, AFP $\leq 200 \mathrm{ng} / \mathrm{mL}$, absence of vascular invasion, and Barcelona Clinic Liver Cancer (BCLC) stage B (Table 8 ).

Thus, because lenvatinib [20] is still effective in laterline therapy, sequential therapy with sorafenib followed by regorafenib and then lenvatinib, or with sorafenib followed by lenvatinib, is effective in patients with good liver function and nonaggressive disease, as evidenced by the absence of vascular invasion and low AFP.

A recent multicenter research group study by Kobayashi et al. [21] compared OS after sequential therapy over 3 periods (Table 9). In period I, from 2009 to 2012, sorafenib was used as monotherapy only; in period II, from 2013 to 2016, and period III, from 2017 to 2019, regorafenib and lenvatinib were added as muti-drug sequential therapy in some patients. The median OS was 10.4 months in period I, 11.3 months in period II, and 15.2 months in period III, showing a trend toward longer survival over time (Table 9).

Subgroup analysis in 582 patients with BCLC-C advanced-stage HCC also showed significant improvement in survival over time, from 8.7 months in period I to 10.8 months in period II, and then 13.3 months in period III (Table 9). Many different drugs were incorporated into therapy in period III, which suggests that sequential therapy was a critical factor for extending survival.

\section{Future Direction of Multi-Drug Sequential Therapy}

Recently, atezolizumab plus bevacizumab combination immunotherapy has been approved to treat unresectable HCC worldwide based on the results of IMbrave150 trial, in which the better OS and PFS by this combination therapy over sorafenib were demonstrated [22]. Therefore, first-line systemic therapy in HCC would be replaced by atezolizumab plus bevacizumab combination therapy instead of lenvatinib or sorafenib (Fig. 1). Subsequently, lenvatinib and sorafenib will be the second-line agents and other agents (regorafenib, ramucirumab, and cabozantinib) will be the third-line agents (Fig. 1). Recently, Aoki et al. [23] published very interesting data. Lenvatinib treatment following failure of immune checkpoint inhibitor (ICI) therapy provides very promising efficacy in terms of ORR (mRECIST), DCR (mRECIST), PFS and OS (from the first-line ICI therapy) which were $55.6 \%, 86.1 \%, 10.0$ months (95\% CI, 8.311.8 ), and 29.8 months (95\% CI, 25.3-34.4).

The reason for these favorable results can be attributed to the following 2 points. First, anti-VEGF activity of lenvatinib improved the tumor microenvironment (TME) from immune suppressive to immune permissive during the durable binding activity of ICI to $\mathrm{CD} 8^{+} \mathrm{T}$ cells for several months [24]. Thus, exhausted $\mathrm{T}$ cell will be restored both by PD-1/PD-L1 blockade and improvement of TME. Second, it is reported that HCC with $\mathrm{WNT} / \beta$-catenin mutation is classified into immune cold tumor and therefore does not respond to ICI therapy $[25,26]$. However, it is reported that $\mathrm{WNT} / \beta$-catenin mutation correlate very well with increased expression of FGFR4 [27], and therefore, high response rate and favorable PFS in HCCs with high expression of FGFR4 are obtained [27] because lenvatinib has a strong inhibitory effect of FGFR4 signaling pathway [28]. 
Table 9. Impact of treatment period on OS in patients who received systemic therapy

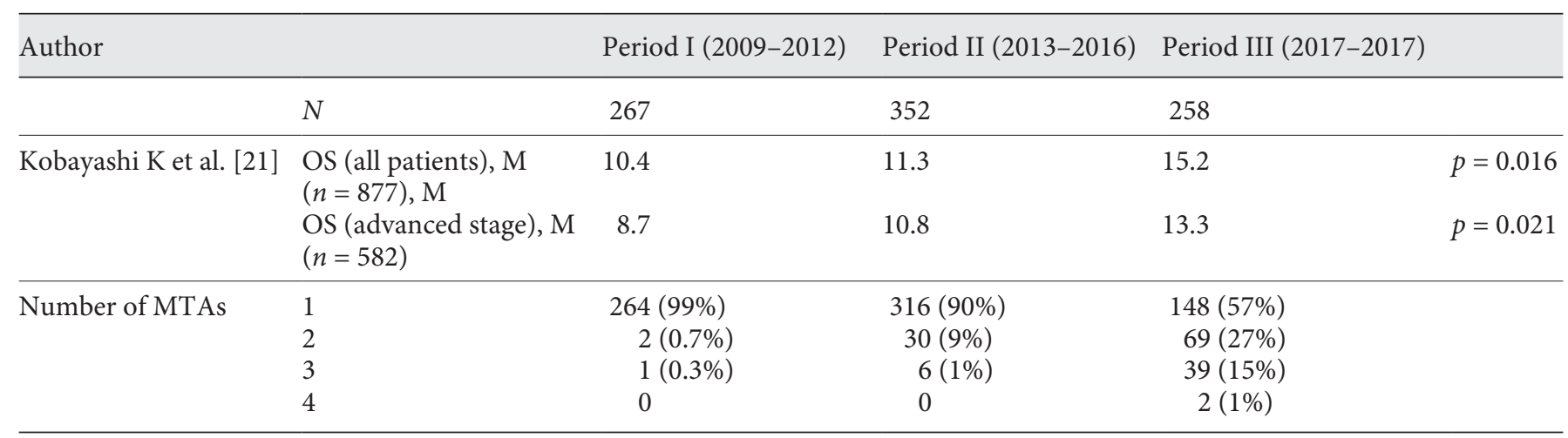

OS, overall survival; MTA, molecular targeted agent. Modified from Ref. [20].

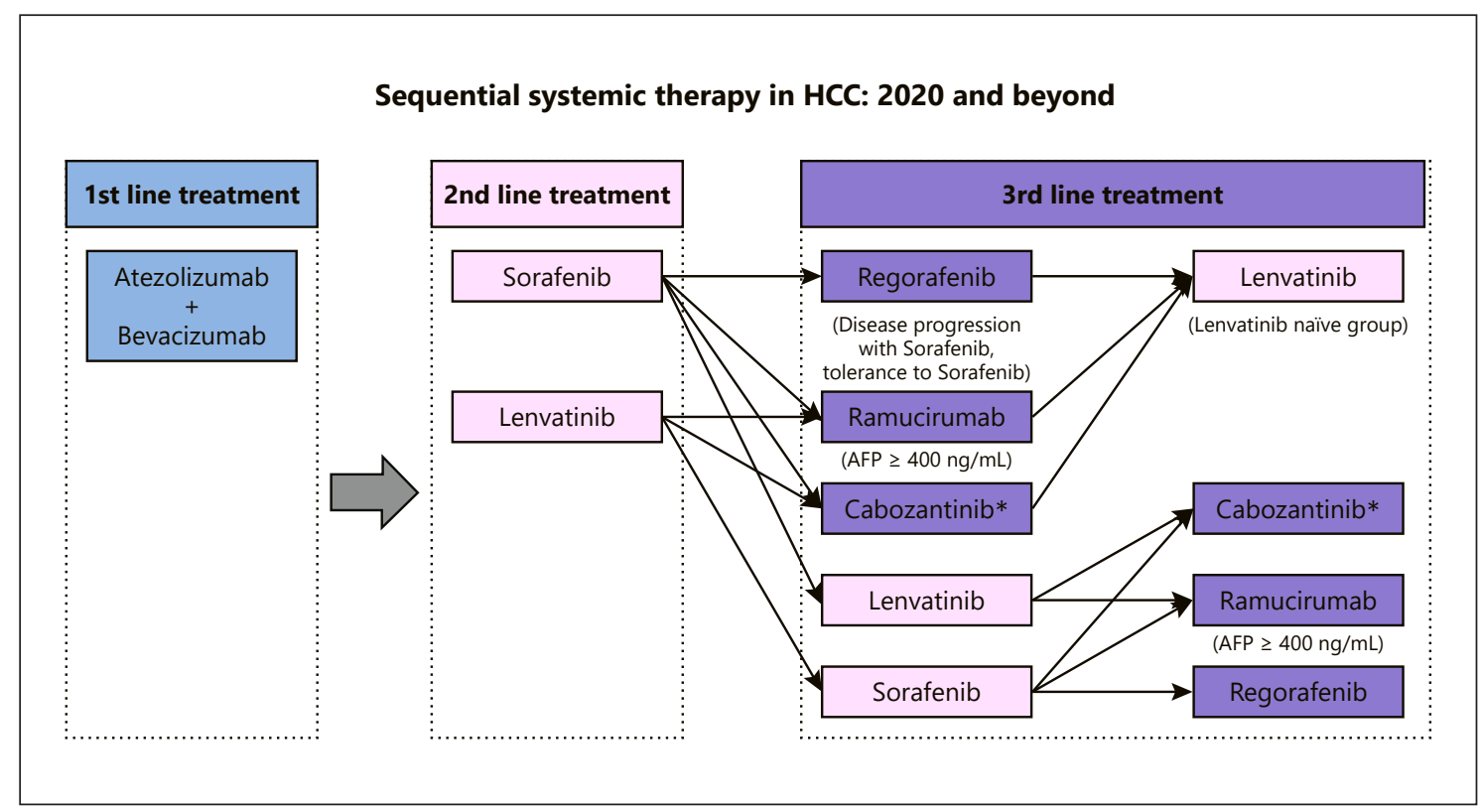

Fig. 1. Sequential systemic therapy in HCC: 2020 and beyond. HCC, hepatocellular carcinoma; AFP, alpha-fetoprotein.

Considering these favorable effects of Lenvatinib after failure of ICI therapy, it is suggested that after failure of atezolizumab plus bevacizumab, lenvatinib will be the first choice of second-line treatment. After lenvatinib, there are many combination of possible sequential therapies (Fig. 1). At the present, however, it is difficult to determine which sequencing will be the best choice. This clinical question must be solved in the real-world practice setting or prospective registration study such as the PRISM study (UMIN 000040488).

Impact of Multi-Drug Sequential Therapy in HCC

\section{Conclusion}

Real-world data from many different studies show that (1) survival in advanced HCC has undoubtedly improved with the introduction of molecular targeted therapy sorafenib and the experience in managing adverse events; (2) sequential therapy combining multiple drugs has improved survival in patients with advanced HCC by adding further lines of treatment (second, third, and fourth) to previous monotherapy $[29,30]$; and (3) when performing muti-drug sequential therapy, it is important to start sys-

Liver Cancer 2021;10:1-9 
temic therapy when the patient shows a good disease condition, namely, ALBI grade 1, a Child-Pugh score of 5, no vascular invasion, and low AFP levels. Lastly, it should be emphasized that avoiding the overuse of transarterial chemoembolization (TACE) helps to extend survival because overuse of ineffective TACE reduces liver function in patients with intermediate-stage HCC, and subsequently, many patients will not be eligible for systemic therapy [31-38].

In order to avoid the deterioration of liver function by repeated TACE, concept of TACE unsuitability has been proposed and published by the APPLE Association as an "APPLE Consensus Statement on Treatment Strategy in Intermediate-Stage HCC” [37]. This concept was established based on the concept of TACE failure/refractoriness proposed by the Japan Society of Hepatology [39], but "concept of TACE unsuitability" by APPLE Consensus was further refined to preserve liver function by avoiding ineffective/unnecessary TACE procedure in patients who easily become TACE failure/refractoriness.

\section{Statement of Ethics}

Not applicable.

\section{Conflict of Interest Statement}

Lectures: Eisai, Bayer, and MSD; grants: EA Pharma, Eisai, Gilead, Takeda, Otsuka, and Taiho; advisory consulting: Eisai, Ono, MSD, and BMS. Masatoshi Kudo, MD, PhD, is the editor-in-chief of Liver Cancer.

\section{Funding Sources}

The authors did not receive any funding.

\section{Author Contributions}

M. Kudo conceived, wrote, and approved the final manuscript.

\section{References}

1 Llovet JM, Ricci S, Mazzaferro V, Hilgard P, Gane E, Blanc JF, et al. Sorafenib in advanced hepatocellular carcinoma. N Engl J Med. 2008;359(4):378-90.

2 Cheng AL, Kang YK, Chen Z, Tsao CJ, Qin S, Kim JS, et al. Efficacy and safety of sorafenib in patients in the Asia-Pacific region with advanced hepatocellular carcinoma: a phase III randomised, double-blind, placebo-controlled trial. Lancet Oncol. 2009;10(1):25-34.

3 Bouattour M, Mehta N, He AR, Cohen EI, Nault JC. Systemic treatment for advanced hepatocellular carcinoma. Liver Cancer. 2019;8(5):341-58.

4 Rimassa L, Pressiani T, Merle P. Systemic treatment options in hepatocellular carcinoma. Liver cancer. 2019;8(6):427-46.

5 Sensui M, Ogasawara S, Ooka Y, Kobayashi K, Maruta S, Kanzaki H, et al. Survival among patients with advanced hepatocellular carcinoma in the pre-TKI versus TKI eras. Vienna, Austria: EASL; 2019 Apr 10-14.

6 Raoul JL, Adhoute X, Penaranda G, Perrier H, Castellani P, Oules V, et al. Sorafenib: experience and better manage-ment of side effects improve overall survival in hepatocellular carcinoma patients: a real-life retrospective analysis. Liver Cancer. 2019;8(6):457-67.

7 Tovoli F, Ielasi L, Casadei-Gardini A, Granito A, Foschi FG, Rovesti G, et al. Management of adverse events with tailored sorafenib dosing prolongs survival of hepatocellular carcinoma patients. J Hepatol. 2019;71(6):1175-83.
8 Finn RS, Merle P, Granito A, Huang YH, Bodoky G, Pracht M, et al. Outcomes of sequential treatment with sorafenib followed by regorafenib for HCC: additional analyses from the phase III RESORCE trial. J Hepatol. 2018;69(2):353-8.

9 Ogasawara S, Ooka Y, Itokawa N, Inoue M, Okabe S, Seki A, et al. Sequential therapy with sorafenib and regorafenib for advanced hepatocellular carcinoma: a multicenter retrospective study in Japan. Invest New Drugs. 2020; 38(1):172-80.

10 Hiraoka A, Kumada T, Atsukawa M, Hirooka M, Tsuji K, Ishikawa T, et al. Important clinical factors in sequential therapy including lenvatinib against unresectable hepatocellular carcinoma. Oncology. 2019;97(5):277-85.

11 Hiraoka A, Kumada T, Fukunishi S, Atsukawa M, Hirooka M, Tsuji K, et al. Post-progression treatment eligibility of unresectable hepatocellular carcinoma patients treated with lenvatinib. Liver Cancer. 2020;9(1):73-83.

12 Wang W, Tsuchiya K, Kurosaki M, Yasui Y, Inada K, Kirino S, et al. Sorafenib-regorafenib sequential therapy in japanese patients with unresectable hepatocellular carcinoma-relative dose intensity and post-regorafenib therapies in real world practice. Cancers. 2019; 11(10): 1517

13 Ogasawara S, Chiba T, Ooka Y, Suzuki E, Maeda T, Yokoyama M, et al. Characteristics of patients with sorafenib-treated advanced hepatocellular carcinoma eligible for secondline treatment. Invest New Drugs. 2018;36(2): 332-9.
14 Kuzuya $\mathrm{T}$, Ishigami M, Ito T, Ishizu $\mathrm{Y}$, Honda $\mathrm{T}$, Ishikawa $\mathrm{T}$, et al. Clinical characteristics and outcomes of candidates for second-line therapy, including regorafenib and ramucirumab, for advanced hepatocellular carcinoma after sorafenib treatment. Hepatol Res. 2019;49(9):1054-65.

15 Uchikawa S, Kawaoka T, Aikata H, Kodama K, Nishida Y, Inagaki Y, et al. Clinical outcomes of sorafenib treatment failure for advanced hepatocellular carcinoma and candidates for regorafenib treatment in real-world practice. Hepatol Res. 2018;48(10):814-20.

16 Terashima T, Yamashita T, Sunagozaka H, Arai K, Kawaguchi K, Kitamura K, et al. Analysis of the liver functional reserve of patients with advanced hepatocellular carcinoma undergoing sorafenib treatment: prospects for regorafenib therapy. Hepatol Res. 2018; 48(12):956-66.

17 Yukimoto A, Hirooka M, Hiraoka A, Michitaka $\mathrm{K}$, Ochi $\mathrm{H}$, Joko $\mathrm{K}$, et al. Using ALBI score at the start of sorafenib treatment to predict regorafenib treatment candidates in patients with hepatocellular carcinoma. Jpn J Clin Oncol. 2019;49(1):42-7.

18 Takada H, Kurosaki M, Tsuchiya K, Komiyama $Y$, Itakura J, Takahashi $Y$, et al. Baseline and early predictors of good patient candidates for second-line after sorafenib treatment in unresectable hepatocellular carcinoma. Cancers. 2019;11(9):1256. 
19 Kirstein MM, Scheiner B, Marwede T, Wolf C, Voigtländer T, Semmler G, et al. Sequential systemic treatment in patients with hepatocellular carcinoma. Aliment Pharmacol Ther. 2020;52(1):205-12.

20 Kudo M, Finn RS, Qin S, Han K-H, Ikeda K, Piscaglia F, et al. Lenvatinib versus sorafenib in first-line treatment of patients with unresectable hepatocellular carcinoma: a randomised phase 3 non-inferiority trial. Lancet. 2018;391(10126):1163-73.

21 Kobayashi K, Ogasawara S, Iwanaga T, Unozawa H, Sakuma T, Fujita N, et al. Effects of molecular target agent therapy in advanced hepatocellular carcinoma: a multicenter, retrospective study. ILC. 2020:114.

22 Finn RS, Qin S, Ikeda M, Galle PR, Ducreux M, Kim TY, et al. Atezolizumab plus bevacizumab in unresectable hepatocellular carcinoma. N Engl J Med. 2020;382(20):1894-905.

23 Aoki T, Kudo M, Ueshima K, Morita M, Chishina H, Takita M, et al. Exploratory analysis of lenvatinib therapy in patients with unresectable hepatocellular carcinoma who have failed prior PD-1/PD-L1 checkpoint blockade. Cancers. 2020;12(10):3048.

24 Osa A, Uenami T, Koyama S, Fujimoto K, Okuzaki D, Takimoto T, et al. Clinical implications of monitoring nivolumab immunokinetics in non-small cell lung cancer patients. JCI Insight. 2018;3(19).

25 Sia D, Jiao Y, Martinez-Quetglas I, Kuchuk O, Villacorta-Martin C, Castro de Moura M, et al. Identification of an immune-specific class of hepatocellular carcinoma, based on molecular features. Gastroenterology. 2017;153(3): $812-26$.

26 Harding JJ, Nandakumar S, Armenia J, Khalil DN, Albano M, Ly M, et al. Prospective geno- typing of hepatocellular carcinoma: clinical implications of next-generation sequencing for matching patients to targeted and immune therapies. Clin Cancer Res. 2019;25(7): 2116-26.

27 Yamauchi M, Ono A, Ishikawa A, Kodama K Uchikawa S, Hatooka H, et al. Tumor fibroblast growth factor receptor 4 level predicts the efficacy of lenvatinib in patients with advanced hepatocellular carcinoma. Clin Transl Gastroenterol. 2020;11(5):e00179.

28 Tohyama O, Matsui J, Kodama K, Hata-Sugi N, Kimura T, Okamoto K, et al. Antitumor activity of lenvatinib (e7080): an angiogenesis inhibitor that targets multiple receptor tyrosine kinases in preclinical human thyroid cancer models. J Thyroid Res. 2014;2014:638747.

29 Alsina A, Kudo M, Vogel A, Cheng AL, Tak WY, Ryoo BY, et al. Effects of subsequent systemic anticancer medication following firstline lenvatinib: a post hoc responder analysis from the phase 3 REFLECT study in unresectable hepatocellular carcinoma. Liver Cancer. 2020;9(1):93-104.

30 Matsuki R, Kawai K, Suzuki Y, Kogure M, Nakazato T, Naruge D, et al. Pathological complete response in conversion hepatectomy induced by lenvatinib for advanced hepatocellular carcinoma. Liver Cancer. 2020;9(3):358-60.

31 Arizumi T, Minami T, Chishina H, Kono M, Takita M, Yada N, et al. Time to transcatheter arterial chemoembolization refractoriness in patients with hepatocellular carcinoma in kinki criteria stages B1 and B2. Dig Dis. 2017; 35(6):589-97.

32 Arizumi T, Ueshima K, Minami T, Kono M, Chishina $\mathrm{H}$, Takita $\mathrm{M}$, et al. Effectiveness of Sorafenib in patients with transcatheter arterial chemoembolization (TACE) refractory and intermediate-stage hepatocellular carcinoma. Liver Cancer. 2015;4(4):253-62.

33 Arizumi T, Ueshima K, Iwanishi M, Minami $\mathrm{T}$, Chishina $\mathrm{H}$, Kono M, et al. Validation of a modified substaging system (Kinki Criteria) for patients with intermediate-stage hepatocellular carcinoma. Oncology. 2015;89(Suppl 2):47-52.

34 Hiraoka A, Kumada T, Kudo M, Hirooka M, Koizumi Y, Hiasa Y, et al. Hepatic function during repeated TACE procedures and prognosis after introducing sorafenib in patients with unresectable hepatocellular carcinoma: multicenter analysis. Dig Dis. 2017;35(6): $602-10$

35 Hiraoka A, Kumada T, Michitaka K, Kudo M. Newly proposed ALBI grade and ALBI-T score as tools for assessment of hepatic function and prognosis in hepatocellular carcinoma patients. Liver Cancer. 2019;8(5):312-25.

36 Kudo M. A paradigm change in the treatment strategy for hepatocellular carcinoma. Liver Cancer. 2020;9(4):367-77.

37 Kudo M, Han KH, Ye SL, Zhou J, Huang YH, Lin SM, et al. A changing paradigm for the treatment of intermediate-stage hepatocellular carcinoma: Asia-Pacific primary liver cancer expert consensus statements. Liver Cancer. 2020;9(3):245-60.

38 Kudo M. A new treatment option for intermediate-stage hepatocellular carcinoma with high tumor burden: initial lenvatinib therapy with subsequent selective TACE. Liver Cancer. 2019;8(5):299-311.

39 Kudo M, Matsui O, Izumi N, Kadoya M, Okusaka T, Miyayama S, et al. Transarterial chemoembolization failure/refractoriness: JSHLCSGJ Criteria 2014 update. Oncology. 2014; 87(Suppl 1):22-31. 